\title{
Equilibrium of Carbon and Oxygen in Molten Iron Saturated with Carbon*
}

\author{
By Yoshitaka Nakagawa,** Koreaki Suzuki** \\ and Masaru Fukumoto**
}

\begin{abstract}
It has been known experimentally that oxygen contents in cast iron products often show remarkably scattering values even in a same kind of products, the unexpectedly high or low values of which are hardly comparable with those evaluated from previous works on the equilibrium between carbon and oxygen in carbonsaturated molten iron. This can be attributed to the difficulty in determining the oxygen content in cast iron owing to the presence of graphite. In order to examine the equilibrium of carbon and oxygen in carbonsaturated molten iron, experiments were carried out in the graphite crucible under $\mathrm{CO}$ atmosphere by means of a sampling method established by the present authors: The method consisted of sucking white iron samples from the melt by a thin silica tube and immersion into mercury. Analysis of oxygen was carried out by measuring the electric conductivity in argon-carrier fusion which has the accuracy of less than \pm 2 p.p.m. within the range of less than the 10 p.p.m. oxygen eontent.
\end{abstract}

The results obtained are as follows:

(1) The solubility of earbon in molten iron will be expressed, by

$$
\mathrm{C} \%=1.33+2.59 \times 10^{-3} \times t^{\circ} \mathrm{C} .
$$

(2) Relations between carbon and oxygen in carbon-saturated molten iron will be

$$
\begin{array}{ll}
\mathrm{C}(\mathrm{g})+\mathrm{O}=\mathrm{CO}, & \log K_{4}\left(=P_{\mathrm{CO} 2} / P_{\mathrm{CO}} \times 0\right)=9,018 / T-6.045, \\
\log K_{3}\left(=P_{\mathrm{CO}} / 0\right)=613 / T+2.775, & \mathrm{C}+\mathrm{O}=\mathrm{CO} \text { (carbon saturation), } \\
\mathrm{O}+\mathrm{CO}=\mathrm{CO}_{2} \text { (carbon saturation), } & \log K_{7}\left(=P_{\mathrm{CO} / \mathrm{C} \% \times 0 \%)=1.239 / T+1.711 .}\right.
\end{array}
$$

(3) The activity coefficient of carbon and oxygen in carbon-saturated molten iron will be

$$
\begin{aligned}
& \log f_{c}=-847 / T+2.055-\log \left\{1.33+2.59 \times 10^{-3}(T-273)\right\}, \\
& \log f_{c}=300 / T-1.283 .
\end{aligned}
$$

(4) The oxygen content of carbon-saturated molten iron is extremely low. Consequently, the equilibrium product $(C) .(0)$ does not show a large value, and the activity coefficient of oxygen obtained is not an extremely small value.

(5) To determine the exact oxygen content in carbon-saturated molten iron it is essential to prevent graphite from precipitation in samples as much as possible. Furthormore it is necessary to establish an analytical method, which is possible to determine an extremely low oxygen content up to the level of $0.0001 \%$.

(Received September 8, 1965)

\section{Introduction}

There have been many investigations(1) (5) that oxygen in cast iron gives an important influence on properties of irons. Many unknown problems, however, still remain with respect to the quantitative influence of oxygen on their properties. The experiments at our plant have revealed that of oxygen contents in cast iron products often show remarkably scattering values even in a same or similar kind of products and the values are unexpectedly high or low as compared with those evaluated from previous

* This paper was published in Japanese in the Journal of the Japan Institute of Metals, 30 (1966), 50.

** Research Center Muroran Plant the Japan Steel Work, Muroran, Japan.

(1) H. Morrogh: Foundry Trade Journal, (1955), Dec., 22 723.

(2) L. Smith: Foundry Trade Journal, (1954), March, 18 233.

(3) Madono: Tetsu To Hagane, 27 (1941), 832.

(4) L. Boegehold: Trans. of ASM, (1938), 1084.

(5) Homma: Trans. JIM, 16 (1952), 260, 265, 486, 547, 607. works on the equilibrium between carbon and oxygen in molten iron saturated with carbon. A major cause of it is the difficulty of precisely analyzing the oxygen content in cast iron, but it seems necessary to reexamine the conventional equilibrium values between carbon and oxygen in carbon-saturated molten iron.

Therefore, investigations were first made on the sampling and preparation methods to precisely determine oxygen contents in molten iron, by establishing an appropriate method, and the equilibrium between carbon and oxygen in carbon-saturated molten iron was examined.

\section{Experimental Procedure}

\section{Analytical method and its accuracy}

Analysis of oxygen were carried out by measuring the electric conductivity in an argon-carrier fusion. In order to determine the analytical accuracy of this method, comparison was made with the vacuum-fusion micro-orsat method and the vacuum fusion-measuring pressure method, and the reproducibility of the present method was examined, using the standard 
Table 1 Analytical conditions

\begin{tabular}{c|c|c|c|c|c}
\hline Method & $\begin{array}{c}\text { Preparation } \\
\text { temp. }\left({ }^{\circ} \mathrm{C}\right)\end{array}$ & $\begin{array}{c}\text { Preparation } \\
\text { temp. (hr) } \\
\text { time }\end{array}$ & $\begin{array}{c}\text { Analysis temp. } \\
\left({ }^{\circ} \mathrm{C}\right)\end{array}$ & $\begin{array}{c}\text { Extraction time } \\
\text { of gas (min) }\end{array}$ & $\begin{array}{c}\text { Sample wt. } \\
(\mathrm{g})\end{array}$ \\
\hline $\begin{array}{c}\text { Vacuum fusion } \\
\text { (micro-orsat) }\end{array}$ & $2000-2100$ & $2.5 \sim 3.0$ & $1850-1900$ & $15 \sim 20$ & $5-10$ \\
\hline $\begin{array}{c}\text { Inert-gas fusion } \\
\text { (meassuring electric } \\
\text { conductivity) }\end{array}$ & 22002250 & 0.51 .0 & $1850-1900$ & $2.5-5$ & $1-2$ \\
\hline $\begin{array}{c}\text { Vacuum fusion } \\
\text { (messuring pressure) }\end{array}$ & $2100 \sim 2200$ & $2.0-2.5$ & $1850-1900$ & $3-5$ & $0.5-1$ \\
\hline \hline
\end{tabular}

Table 2a Oxygen analysis by vacuum fusion and inert-gas fusion

(standard sample B)

\begin{tabular}{|c|c|c|c|}
\hline Method & Oxygen content, (ppm) & $\begin{array}{l}\text { Mean value } \\
\text { (ppm) }\end{array}$ & $\begin{array}{l}\text { Standard } \\
\text { deviation }\end{array}$ \\
\hline $\begin{array}{l}\text { Vacuum fusion } \\
\text { (micro-orsat) }\end{array}$ & $\begin{array}{l}35,35,36,37,37,37,38,39,39,39,41 \\
41,42,42,43,43,44,44,45,46,47,48 \\
49,49\end{array}$ & $\begin{array}{l}41.5 \\
n\end{array}=24$ & 4.3 \\
\hline $\begin{array}{l}\text { Inert gas fusion } \\
\text { (measuuring elecrtic } \\
\text { conductivity) }\end{array}$ & $\begin{array}{l}38,39,40,41,41,42,43,43,43,45,46, \\
46,46,47,48,48,48,48,49,49,49,50 \\
51,51,51,\end{array}$ & $\begin{aligned} 45.4 & =25\end{aligned}$ & 3.9 \\
\hline $\begin{array}{l}\text { Vacuum fusion } \\
\text { (meassuring pressure) }\end{array}$ & $\begin{array}{l}40,41,41,42,43,43,43,43,43,44,44 \\
44,45,47,48,48,49,49,50,50,50,51, \\
51,51,\end{array}$ & $\begin{array}{l}45.8 \\
n\end{array}=24$ & 4.0 \\
\hline
\end{tabular}

$n$; numbers of sample

oxygen contents are tabulated from the side of lower values

Table 2b Reproduciablity of inert-gas fusion.

\begin{tabular}{|c|c|c|c|}
\hline $\begin{array}{l}\text { Standard } \\
\text { sample }\end{array}$ & Oxygen content (ppm) & $\begin{array}{l}\text { Mean value } \\
(\mathrm{ppm})\end{array}$ & $\begin{array}{l}\text { Standard } \\
\text { deviation }\end{array}$ \\
\hline$n=24$ & 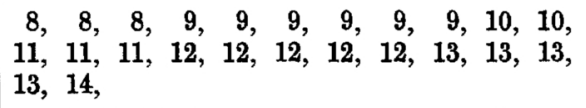 & 10.7 & 1.9 \\
\hline$n=24$ & $\begin{array}{l}4,4,4,4,4,5,5,5,5,5,5,5,6,6, \\
6,7,7,7,7,7,8,8,8,8,\end{array}$ & .8 & 1.5 \\
\hline
\end{tabular}

samples with varying oxygen contents.

The analytical conditions and results of each method are shown in Table 1 and Tables $2 a$ and $2 b$, respectively.

From the tables it can be said the results by measuring the electric conductivity in the argon carrier fusion almost coincided with those of the other method, and the reproducibility was also confirmed to be highly reliable.

However, to improve the accuracy in this experiment the weight of samples for analysis is determined to be more than $5 \mathrm{gm}$. In this case, the accuracy became higher almost two times that of the conventional weight; the accuracy was less than \pm 2 p.p.m. (reliability; $95 \%$ ) whithin the range of less than the 10 p.p.m. oxygen content.

\section{Analysis of carbon}

Carbon contents in the samples weighing 0.2 to 0.3 gm. were determined by the combustion-coulometric method. The analytical accuracy was $\pm 0.07 \%$ within the range of carbon contents in this experiment.
3. Sampling and preparation methods for oxygen analysis in molten iron saturated with carbon

Sampling methods from carbon-saturated molten iron in this experiment can be conventionally divided into two; one is to cut off samples for analysis from iron solidified quickly in the crucible and the other is to suck up and quecnh molten iron by using a thin tube.

\section{(1) The method to rapidly solidify molten iron} in the crucible

This method was investigated by blowing argon gas against molten iron in the reaction tube (hereafter called A-apparatus) used for the experiment of equilibrium shown in Fig. 5 and by using another apparatus (B-apparatus) shown in Fig. 1 in order to make blowing stronger.

Experiment No. 1 Experiment No. 2

A) Apparatus: A B

B) Crucible: graphite crucible $(15 \mathrm{~mm}$ in i.d., $60 \mathrm{~mm}$ in height, $5 \mathrm{~mm}$ in thickness) 


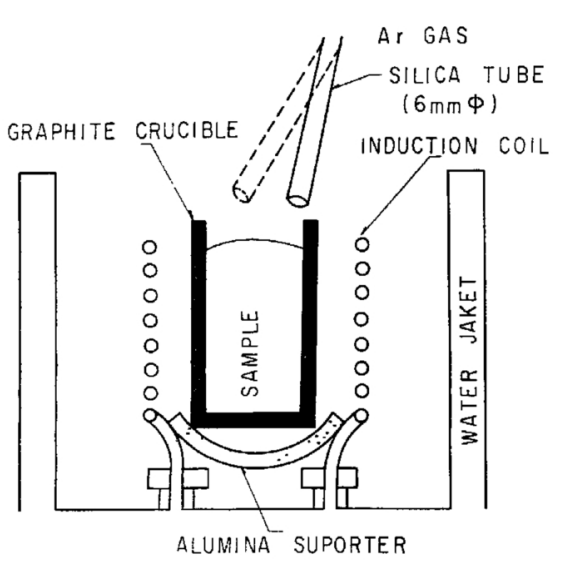

Fig. 1 Apparatus for a quick solidifing test with Ar jet

Experiment No. $1 \quad$ Experiment No. 2

C) Material: electrolytic iron saturated with carbon

D) Weight: $50 \mathrm{gm}$.

E) Atmosphere $\mathrm{CO}$

air

F) Temperature $1350^{\circ} \mathrm{C}$ held for 15 minutes

G) Cooling (Experiment No. 1)

Blow argon gas $\left(20^{\circ} \mathrm{C}\right)$ against the surface of molten iron at the rate of $3000 \mathrm{cc} / \mathrm{min}$ immediately after putting off the power source of the high frequency induction furnace.

(Experiment No. 2)

Blow argon gas $\left(20^{\circ} \mathrm{C}\right)$ against molten iron at the rate of $10,000 \mathrm{cc} / \mathrm{min}$ immediately after putting off the power source of the high frequency induction furnace.

After complete solidification the ingot was cut vertically at the center to investigate its structure, and specimens were cut off from each part of the section to analyze the oxygen content. Fig. 2 shows the macro-structures and the distribution of sampling spots for oxygen analysis in the section, and Photos. 1 and 2 also shows the micro-structures and oxygen contents, respectively.

From these results, it is known that the white iron sample can hardly be obtained by quenching in the melting crucible and even a higher degree of quenching as in experiment No. 2 gives rise to white and mottle portions. Since there is a great difference in the oxygen content by the portions, it is difficult to decide which portion shows a reliable oxygen content in the melt. Accordingly, it is questionable to prepare a sample for oxygen analysis by quenching molten iron in the crucible.

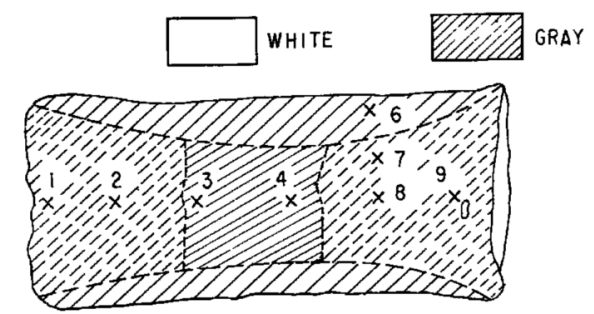

(0) EXPERIMENT N0.1

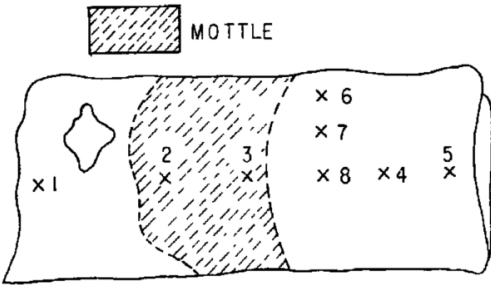

(b) EXPERIMENT NO2

Fig. 2 Location of samples for oxygen analysis and macrostructure of the longitudinal section.

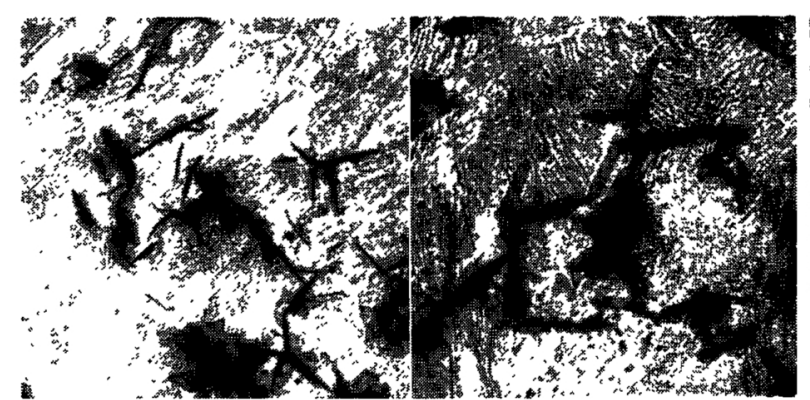

(1) Oxygen content $95 \mathrm{ppm}$
(2) Oxygen content $87 \mathrm{ppm}$

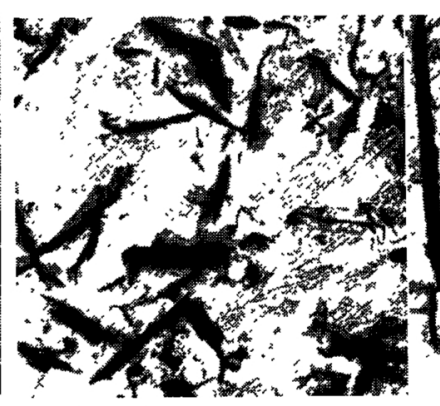

(3) Oxygen content $169 \mathrm{ppm}$

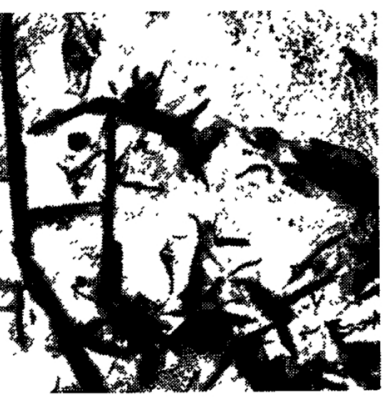

(4) Oxygen content $169 \mathrm{ppm}$

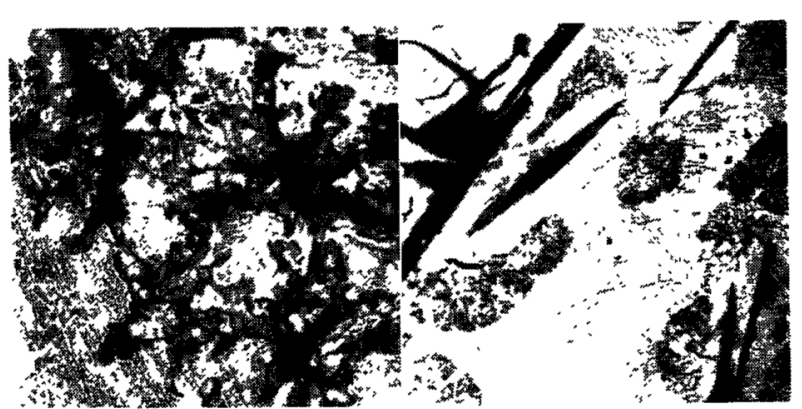

(5) Oxygen content $44 \mathrm{ppm}$
(6) Not analyzed

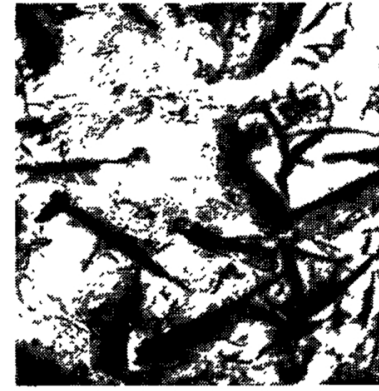

(7) Oxygen content $44 \mathrm{ppm}$

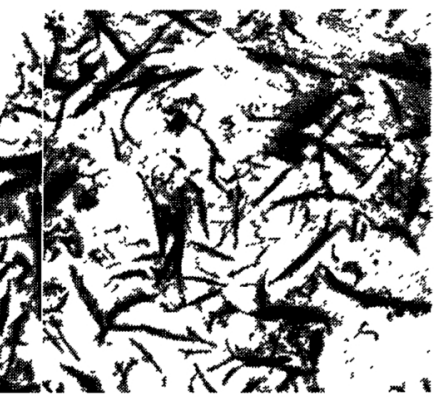

(8) Oxygen content $44 \mathrm{ppm}$

Photo. 1 Structures and oxygen contents in the smaple. (Experiment No. 1) $(\times 100)$ 


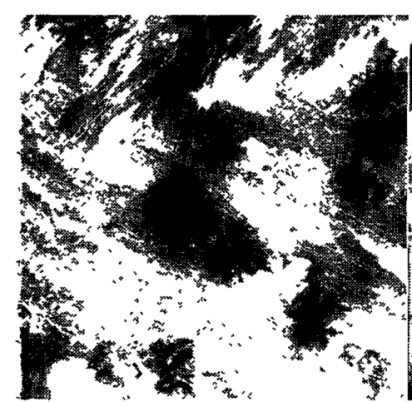

(1) Oxygen content $13 \mathrm{ppm}$

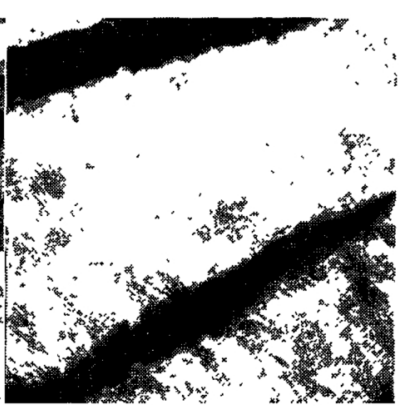

(2) Oxygen content $32 \mathrm{ppm}$

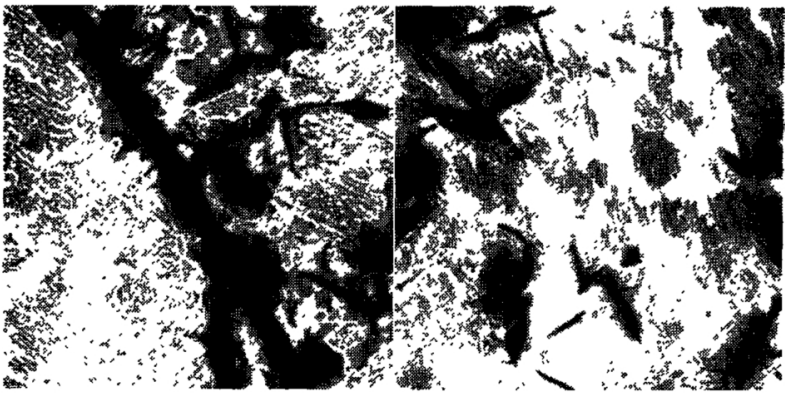

(3) Oxygen content $27 \mathrm{ppm}$
(4) Oxygen content
$10 \mathrm{ppm}$

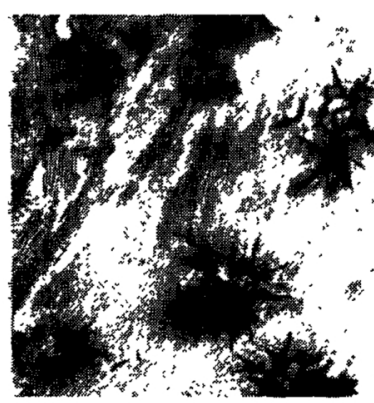

(5) Oxygen content $10 \mathrm{ppm}$

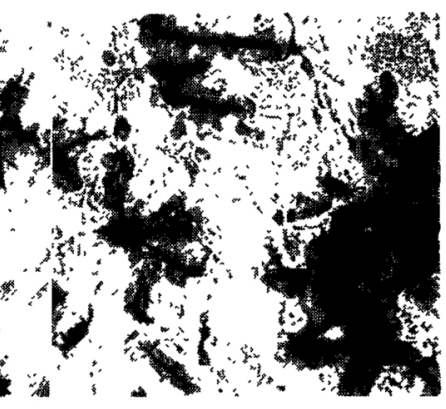

(6) Oxygen content $10 \mathrm{ppm}$

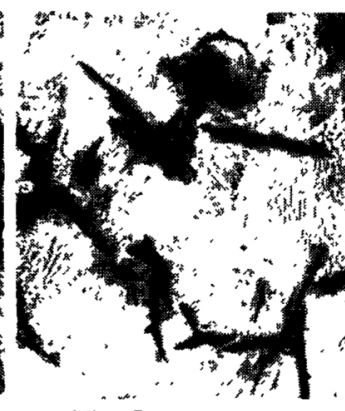

(7) Oxygen content $10 \mathrm{ppm}$

Photo. 2 Structures and oxygen contents in the sample.

(Experiment No. 2) $(\times 100)$

(2) The method to solidify quickly by means of suction of molten iron with a thin tube*

Various investigations were made on the sampling method to suck and quench molten iron by using thin tubes. That is to say, comparison was made on the methods to use the thin tubes with several different inside diameters, vaccum sampling tubes and copper pipes, and the result shows that the most reproduciable values are obtained by the method of sucking molten iron by a $3 \mathrm{~mm}$ I.D. silica tube and quenching in mercury. Fig. 3 shows the result of analysis.

\section{(3) Preparation of the samples for oxygen analysis}

Cutting off specimens sucked from molten iron, grinding and washing were carefully carried out on the basis of a method developed by the authors, and the time from sampling to analysis was shortened as much as possible.

\section{Experimental procedure of equilibriun between carbon and oxygen}

\section{(1) Grucibles and samples}

The crucibles used for the equilibrium experiment are pure graphite ones $27 \mathrm{~mm}$ in i.d., $50 \mathrm{~mm}$ in depth and $5 \mathrm{~mm}$ in thickness, being used for the vacuum fusion method. They were blank heated at $1500^{\circ} \mathrm{C}$ under $10^{-2} \mathrm{mmHg}$ before use. Materials used for the experiment were $120 \mathrm{gm}$. of electrolytic iron melted in the graphite crucible by the high frequency induction furnace and cast into a $26 \mathrm{~mm}$ i.d. metal mould, to which $50 \mathrm{gm}$. of electrolytic iron was added

* Refer a detailed report in "IMONO" published by the Japan Fourdry Association. Vol. 38, p. 78.

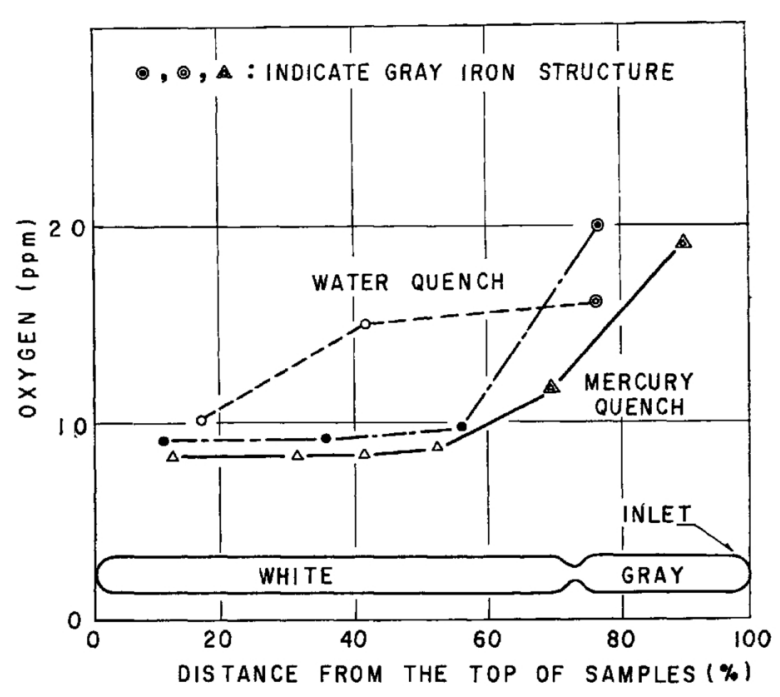

Fig. 3 Distribution of oxygen contents in samples. Samples were sucked from carbon-saturated iron with the $3 \mathrm{~mm}$ silica-tube.

Atmosphere, CO gas; Temperature, $1200^{\circ} \mathrm{C}$

to obtain a higher oxygen content in the iron melt during the early stage of holding.

Chemical compositions of mother materials cast into the metal mould are shown below:

$\begin{array}{ccccc}\mathrm{C} & \mathrm{Si} & \mathrm{Mn} & \mathrm{P} & \mathrm{S} \\ 4.5 \% & \text { tr. } & \text { tr. } & \text { tr. } & \text { tr. }\end{array}$

When electrolytic iron is not added to the samples, it is necessary to reduce the carbon content and kish graphite as much as possible. Otherwise, the experimental performance will become difficult due to the coverage of kish graphite on the surface of the iron melt. 
1. $\mathrm{H}_{2} \mathrm{SO}_{4}$ sol

2. $\mathrm{P}_{2} \mathrm{O}_{5}$

3. $\mathrm{CaCl}_{2}$

4. Soda lime

5. $\mathrm{KOH}$ sol

6. Alkalipyrogallol sol

7. Vacant bottle

C. Inspector for check analysis

F. Reaction chamber

A. CO gas producer

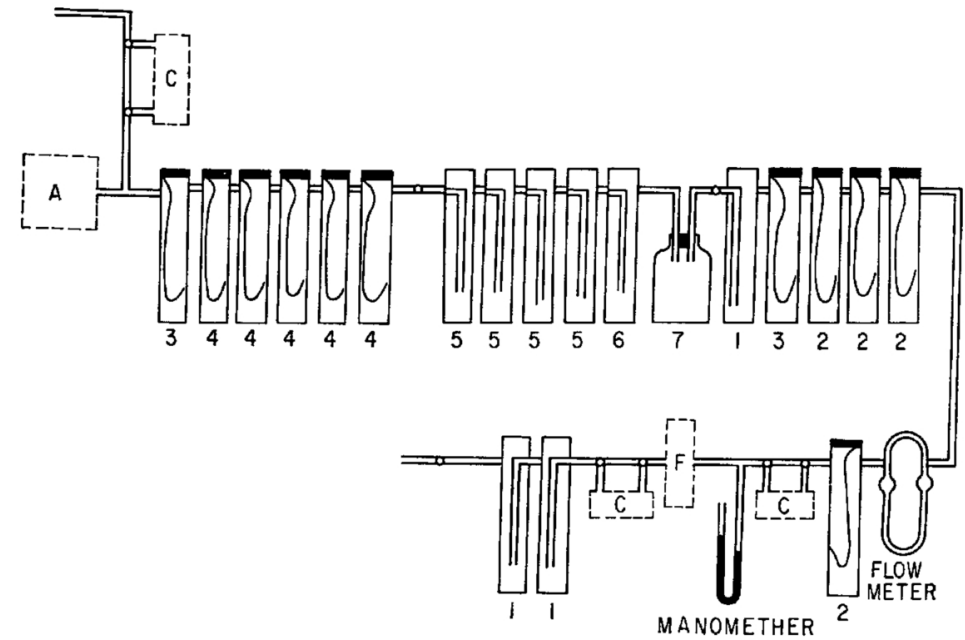

Fig. 4 Schematic diagram of the apparatus.

\section{(2) Experimental apparatus}

Fig. 4 shows a diagram of the experimental apparatus.

(3) Experimental furnace (the reaction tube)

Fig. 5 shows a schematic diagram of the experimental furnace. $\mathrm{CO}$ gas is deduced into the silica tube $65 \mathrm{~mm}$ in i.d. at the height of $35 \mathrm{~mm}$ above the surface of the melt. There are two holes $8 \mathrm{~mm}$ in diameter in the cap of the reaction tube to insert thermo-couples and sampling tubes.

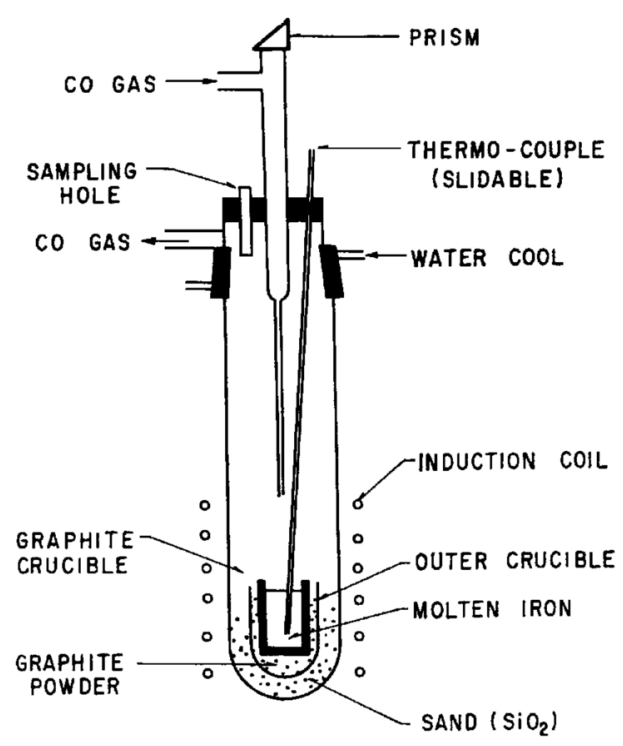

Fig. 5 Reaction chamber.

The graphite crucible for melting was set up in the alumina crucible for shielding, and the gap of the two crucibles was filled with graphite powder dried fully. Silica sand was laid at the bottom of the reaction tube to fix the crucibles.

\section{(4) Carbon monoxide gas producer}

CO gas was produced by a reduction method in which pure $\mathrm{CO}_{2}$ gas $(99.6 \%)$ was made contact with graphite rods at a high temperature. As the graphite rods, poles of high purity for spectroanalysis were used after blankheating for one hour at $1300^{\circ} \mathrm{C}$ under a vacuum of $10^{-2} \mathrm{mmHg}$ to remove moisture. In order to prevent the oxidation of graphite and to remove gases absorbed in graphite solids, argon gas. was carried until the temperature of the reduction furnace rose to $1200^{\circ} \mathrm{C}$.

\section{(5) Purification apparatus}

CO gas produced in the reduction furnace was: purified by soda lime, concentrated potassium hydroxide solution, alkalipyrogallol, concentrated sulfuric acid, and phosphorous pentoxide as shown in Fig. 4.

\section{(6) Temperature measurement}

The optical pyrometer or Pt-PtRh thermocouples. was used to measure the temperature of the iron melt.

The readings of the optical pyrometer werecalibrated with those of the thermocopule under an experimental condition, and the difference between them was found to be within $\pm 5^{\circ} \mathrm{C}$. However, as the measurement of temperature by the optical pyrometer was likely to be disturbed by the presence of kish graphite at a higher temperature, the temperature of the iron melt was controlled by the optical pyrometer and confirmed by the Pt-PtRh thermocouple after sampling. The Pt-PtRh thermocouple was corrected by measuring melting points of electrolyticiron or nickel under argon atmosphere after it had been melted in the magnesia crucible by the high frequency induction furnace under hydrogen atmosphere.

\section{(7) Experimental procedure}

The atmosphere inside the reaction tube was replaced by a carrier of $\mathrm{CO}$ gas for 40 minutes after the sample had been charged in the fully dried crucible in the reaction tube. The gas exhausted from the reaction tube during this replacement was more than $99 \% \mathrm{CO}$ without $\mathrm{CO}_{2}$. The replacement seemed to further proceed because it took 25 minutes to completely melte the sample in the $\mathrm{CO}$ carrier at a high frequency. The sampling was carried out by the method of suction using $3 \mathrm{~mm}$. i.d. silica tubes shown in Fig. 6 after molten iron had reached the equilibrium stage at given temperatures. The inside of silica tubes had been replaced by argon before sampl- 


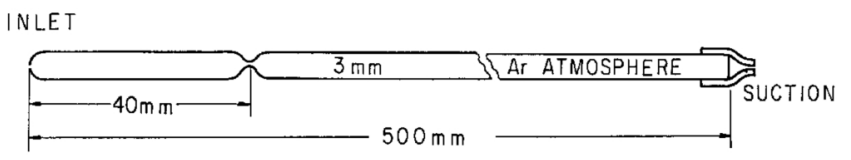

Fig. 6 Sampling tube (Silica tube).

ing, and consequently the samples were prevented from being exposed to the oxidation atmosphere.

The samples sucked to be 140 to $160 \mathrm{~mm}$ in length were quenched by immersing in a mercury bath after sampling. The experimental temperatures were fixed at $1223,1325,1423$, and $1520^{\circ} \mathrm{C}$, and if the atmosphere in contact with the molten samples in the reaction tube at those high temperature reaches the Boudouard equilibrium, a very small amount of $\mathrm{CO}_{2}$ will be present.

The present analytical method is unable to determine the amount of $\mathrm{CO}_{2}$. In fact, the presence of $\mathrm{CO}_{2}$ was not confirmed even by the determination of gas in the molten samples. Thus, the atmosphere was considered to have a composition of the Boudouard equilibrium, judging from the fact that the velocity of reactions was extremely rapid, and the rate of the $\mathrm{CO}$ carrier was selected at $1200 \mathrm{cc} / \mathrm{min}$. The flow of $\mathrm{CO}$ gas was determined in consideration of the temperature drop on the surface of molten iron and conditions for the measurement of temperature by the optical pyrometer. It may be apprehended that the air will be mixed when

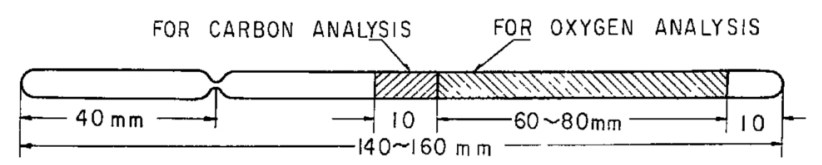

Fig. 7 Sample for oxygen and carbon analyses. the cap on the hole was removed for sampling but it was not problematical because the pressure inside the reaction tube was $8 \mathrm{~mm} \mathrm{Hg}$ higher than that of the atmosphere and the operation was carried out in a short period of time. The analytical samples were prepared from the sucked specimens shown in Fig. 7

\section{Experimental Results}

\section{The time to reach the equilibrium}

The time to reach the equilibrium depends on the carbon or oxygen content in molten iron, heating conditions after melting, and holding temperature. Compositions of the molten smaples were almost constant and the holding time at given temperatures after melting was fixed at 10 minutes in this experiment. The time from the equilibrium state at given temperatures to smapling was determined as follows. As the molten smaples prepared by adding $50 \mathrm{gm}$. of electrolytic iron the $0.065 \%$ oxygen content to about $120 \mathrm{gm}$. of iron with the $4.5 \%$ carbon content, the equilibrium state was always attained from the side of a higher oxygen content and from the side of a lower carbon content. In the preliminary experiment to determine the holding time by sampling, $20 \mathrm{gm}$. of $\mathrm{Fe}_{2} \mathrm{O}_{3}$ powder was added to the molten iron in order to lower the carbon content and to increase the oxygen content after holding at given temperature. The molten iron was in advance melted with $120 \mathrm{gm}$. of iron with the $4.0 \%$ carbon content and $50 \mathrm{gm}$. of electrolytic iron to prolong the time to reach the equilibrium. The sampling was carried out after the addition of $\mathrm{Fe}_{2} \mathrm{O}_{3}$ under the above condition, and the time to reach the equilibria carbon and oxygen was determined, respectively.

The results are shown in Fig. 8.

As shown in Fig. 8, the periods of time to reach the
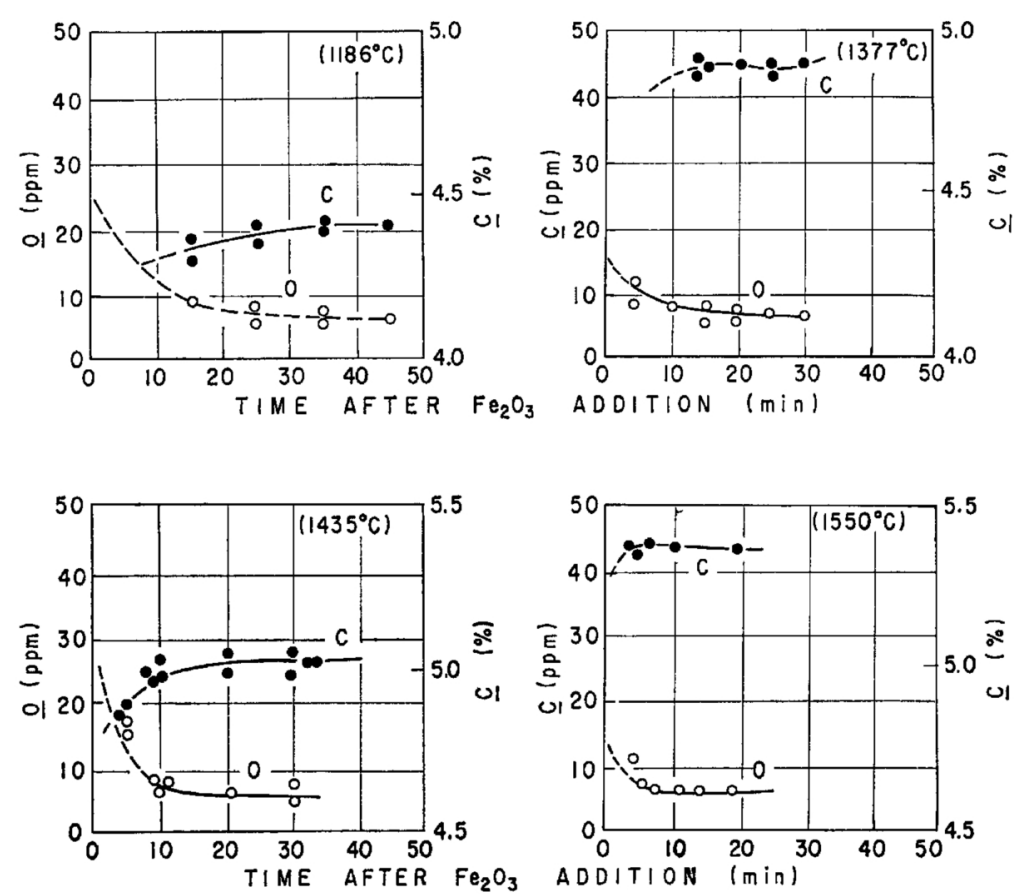

Fig. 8 Variations in carbon and oxygen contents after $\mathrm{Fe}_{2} \mathrm{O}_{3}$ addition. 
equilibria of carbon and oxygen are almost constant, that is 25 minutes at $1186^{\circ} \mathrm{C}$, about 10 minutes at $1370^{\circ} \mathrm{C}$, less than 10 minutes at $1435^{\circ} \mathrm{C}$ and 7 minutes at $1520^{\circ} \mathrm{C}$.

From these results, the holding time in the equilibrium experiment was determined as follows: Experimental temperature $\left({ }^{\circ} \mathrm{C}\right) \quad 1223132514231520$ Holding time (minutes)

$\begin{array}{llll}30 & 20 & 15 & 15\end{array}$

\section{Results and discussion}

Equilibrium experiment for 10 heats were carried out at $1223,1325,1423$ and $1520^{\circ} \mathrm{C}$ by the method discribed already. The results are shown in Tables 3 , 4, 5, and 6 , where $\log K_{3}$ and $\log K_{4}$ will be described later.

Table 3 Experimental results at $1223^{\circ} \mathrm{C}$

\begin{tabular}{|c|c|c|c|c|}
\hline Heat No & C \% & $Q \% \times 10^{4}$ & $\log K_{3}$ & $\log K_{8}$ \\
\hline E-23 & 4.53 & 8 & 3.0969 & 2.4408 \\
\hline $\mathbf{E}-25$ & 4.50 & 6 & 3.2218 & 2.5686 \\
\hline E-26 & 4.48 & 5 & 3.3010 & 2.6498 \\
\hline E-27 & 4.48 & 7 & 3.1549 & 2. 5036 \\
\hline E-28 & 4.52 & 7 & 3.1549 & 2. 4998 \\
\hline $\mathrm{E}-89$ & 4.49 & 6 & 3.2218 & 2. 5696 \\
\hline E-96 & 4.48 & 7 & 3.2549 & 2. 5036 \\
\hline E-97 & 4.48 & 6 & 3.2218 & 2.5706 \\
\hline E-106 & 4.46 & 8 & 3.0969 & 2. 4476 \\
\hline E-107 & 4.54 & 6 & 3.2218 & 2. 5648 \\
\hline
\end{tabular}

Table 4 Experimental results at $1325^{\circ} \mathrm{C}$

\begin{tabular}{c|c|c|c|c}
\hline Heat No & C \% & $\underline{Q} \% \times 10^{4}$ & $\log K_{3}$ & $\log K_{8}$ \\
\hline E-17 & 4.81 & 6 & 3.2218 & 2.5397 \\
E-29 & 4.74 & 5 & 3.3010 & 2.6253 \\
E-108 & 4.79 & 5 & 3.3010 & $\mathbf{6 . 6 2 3 4}$ \\
E-109 & 4.71 & 7 & 3.1549 & 2.4819 \\
E-113 & 4.72 & 7 & 3.1549 & 2.5171 \\
E-119 & 4.74 & 9 & 3.0458 & 2.3700 \\
E-125 & 4.78 & 7 & 3.1549 & 2.4755 \\
E-126 & 4.71 & 8 & 3.0969 & 2.4239 \\
E-142 & 4.79 & 7 & 3.1549 & 2.4746 \\
E-143 & 4.76 & 6 & 3.2218 & 2.5442 \\
\hline
\end{tabular}

Table 5 Experimental results at $1425^{\circ} \mathrm{C}$

\begin{tabular}{|c|c|c|c|c|}
\hline Heat No & c \% & $\underline{Q} \% \times 10^{4}$ & $\log K_{\mathrm{z}}$ & $\log K_{8}$ \\
\hline E-7 & 5.02 & 9 & 3.0458 & 2. 3451 \\
\hline E-15 & 5.04 & 7 & 3.1549 & 2.4525 \\
\hline E-20 & 5.06 & 5 & 3.3010 & 2.5969 \\
\hline $\mathrm{E}-37$ & 4.97 & 5 & 3.3010 & 2.6038 \\
\hline E-117 & 5. 04 & 9 & 3.0458 & 2. 3433 \\
\hline E-118 & 4.99 & 8 & 3.0969 & 2.3988 \\
\hline E-127 & 4.96 & 7 & 3.1549 & 2.4594 \\
\hline E-130 & 5.04 & 7 & 3.1549 & 2.4525 \\
\hline E-131 & 5.01 & 9 & 3.0548 & 2. 3459 \\
\hline E-132 & 5.02 & 8 & 3.0969 & 2. 3962 \\
\hline
\end{tabular}

(1) The solubility and activity coefficient of carbon

The solubility of carbon at each temperature is shown in Fig. 9. The determined values of carbon have an approximately linear relation within the range of the experimental temperatures. The solubility of carbon is shown in the following equation:

$$
\mathrm{C} \%=1.33+2.59 \times 10^{-3} \times t^{\circ} \mathrm{C} \text {. }
$$

Table 6 Experimental results at $1425^{\circ} \mathrm{C}$

\begin{tabular}{c|c|c|c|c}
\hline \hline Heat No & $\underline{\mathrm{C}} \%$ & $\underline{\mathrm{Q}} \% \times 10^{-4}$ & $\log K_{\mathbf{3}}$ & $\log K_{\mathbf{8}}$ \\
\hline $\mathrm{E}-71$ & 5.30 & 7 & 3.1549 & 2.4306 \\
$\mathrm{E}-73$ & 5.26 & 9 & 3.0458 & 2.3248 \\
$\mathrm{E}-75$ & 5.26 & 7 & 3.1549 & 2.4339 \\
$\mathrm{E}-76$ & 5.27 & 6 & 3.2218 & 2.5000 \\
$\mathrm{E}-77$ & 5.22 & 7 & 3.1549 & 2.4372 \\
$\mathrm{E}-78$ & 5.21 & 9 & 3.0458 & 2.3288 \\
$\mathrm{E}-79$ & 5.29 & 9 & 3.0458 & 2.3223 \\
$\mathrm{E}-80$ & 5.27 & 9 & 3.0458 & 2.3239 \\
$\mathrm{E}-81$ & 5.24 & 8 & 3.0969 & 2.3777 \\
$\mathrm{E}-82$ & 5.31 & 6 & 3.2218 & 2.4468 \\
\hline
\end{tabular}

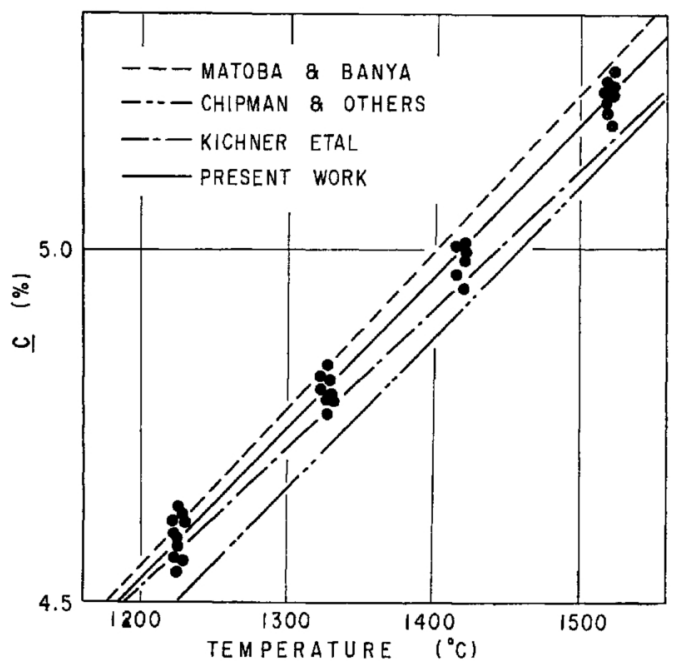

Fig. 9 Effect of temperature on the solubility of carbon in molten iron.

A part of other experimental results is shown in Fig. 9. The results of the present work lie between those by Matoba and Banya(2) by and Chipman et al. The equilibrium relation in carbon-saturated molten iron can be expressed as follows:

$$
\begin{array}{ll}
\mathrm{C}(\mathrm{g})+\mathrm{CO}=2 \mathrm{CO}_{2} & \text { (Boudouard equilibrium). } \\
\mathrm{O}+\mathrm{CO}=\mathrm{CO}_{2} & \text { (Carbon saturation). } \\
\mathrm{C}(\mathrm{g})+\underline{\mathrm{O}}=\mathrm{CO} . & \\
\underline{\mathrm{C}}+\underline{\mathrm{O}}=\mathrm{CO} & \text { (Carbon saturation). }
\end{array}
$$

The phases of gas and molten iron were in the equilibrium state and the gaseous composition seemed to have a Boudouard equilibrium composition. Therefore, the activity coefficient of carbon can be calculated from a combination of Boudouard equations and Matoba and Banya's equations in the dilute solution. When an ideal line of the carbon activity is assumed from Henry's law to be $f_{c}=a_{c} / \underline{\mathrm{C}} \%$, the following formulae will be given:

$$
\left.\begin{array}{l}
\mathrm{C}(\mathrm{g})+\mathrm{CO}_{2}=2 \mathrm{CO} \quad \text { (Boudouard equilibrium) } \\
\log K_{1}\left(=P^{2} \mathrm{co} / P_{\mathrm{co}_{2}}\right)=-8,405 / T+8.820
\end{array}\right\} .
$$

(6) Matoba and Banya: Tetsu To Hagane, 43 (1957), 790.

(7) J. Chimpan et al: Trans. of ASM, 44 (1952), 1215.

(8) J.A. Kichener et al: Trans. of Farady Soc., 48 (1952), 608.

(9) S. Matoba and S. Banya: The Japan Society for the Promotion of Science, The Nineteenth Committee (Steelmaking) - The recommended values on equilibrium between carbon and oxygen (1960). 
Table 7 Summary of experimental results.

\begin{tabular}{c|c|c|c|c|c|c}
\hline \hline Temp. C & $\underline{\mathrm{C}} \%$ & $\underline{\mathrm{Q}} \%$ & $\underline{\mathrm{Q}} \% \times \underline{\mathrm{Q}} \%$ & of from eq. (6) & of from eq. (10) & $f_{c}$ \\
\hline 1200 & 4.44 & 0.00064 & 0.0028 & 0.0833 & 0.0847 & 6.82 \\
1250 & 4.57 & 0.00066 & 0.0030 & 0.0822 & 0.0835 & 6.89 \\
1300 & 4.70 & 0.00068 & 0.0032 & 0.0811 & 0.0820 & 6.99 \\
1350 & 4.83 & 0.00070 & 0.0034 & 0.0800 & 0.0809 & 7.06 \\
1400 & 4.97 & 0.00072 & 0.0036 & 0.0789 & 0.0800 & 7.11 \\
1450 & 5.09 & 0.00074 & 0.0038 & 0.0778 & 0.0789 & 7.19 \\
1500 & 5.22 & 0.00076 & 0.0040 & 0.0767 & 0.0781 & 7.24 \\
1550 & 5.35 & 0.00078 & 0.0042 & 0.0756 & 0.0773 & 7.28 \\
\hline
\end{tabular}

$$
\left.\begin{array}{l}
\underline{\mathrm{C}}+\mathrm{CO}_{2}=2 \mathrm{CO} \quad \text { (Dilute solution) } \\
\log K_{2}\left(=P^{2} \mathrm{Co} / P_{\mathrm{CO}_{2}} \cdot a_{c}\right)=-7,558 / T+6.765
\end{array}\right\} .
$$

From equation (1) or (2), we obtain

$$
f_{c}=K_{1} / K_{2} \times \underline{\mathrm{C}} \% \text {. }
$$

The activity coefficient of carbon $f_{c}$ in carbonsaturated iron can be calculated from the above equation by substituting the solubility of carbon in the formula already given. The function of temperature is expressed by the following equation:

$$
\log f_{c}=-847 / T+2.055-\log (\underline{\mathrm{C}} \%),
$$

where $\mathrm{C} \%$ is the solubility of carbon at $T^{\circ} \mathrm{K}$.

Table 7 shows the results calculated at the representative temperatures.

(2) The oxygen content and the activity coefficient of oxygen in carbon-saturated iron

It is extremely difficult to determine the exact oxygen content in carbon-saturated iron in the light of sampling and analytical accuracy. The analytical results of the samples in which the precipitation of graphite was suppressed as much as possible are shown in Tables $3 \sim 6$.

The equilibrium equation for oxygen in carbonsaturated iron is expressed by

$$
\left.\begin{array}{l}
\mathrm{C}(\mathrm{g})+\mathrm{Q}=\mathrm{CO} \\
K_{3}=P_{\text {co }} / \underline{\mathrm{Q}} \%
\end{array}\right\} .
$$

Values of $\log K_{3}$ in this experiment are shown in Tables 3 6, and the relation between these values and $1 / T$ is shown in Fig. 10. In all the cases, the oxygen content is very low, and the values ranging from 0.0005 to $0.0009 \%$ are within the analytical error of $\pm 0.0002 \%$.

From the above results it can be said that the oxygen content in carbon-saturated iron is not greatly influenced by temperature. This will be further discussed after establishing the sampling and analytical melthods with a higher accuracy. A statistical arrangement of the results in Fig. 10 gives the following equation:

$$
\log K_{3}\left(=P_{\mathrm{co}} / \underline{Q} \%\right)=613 / T+2.775 .
$$

The above equation shows that the oxygen content in carbon-saturated molten iron, increases slightly with the rise of temperature.

The relation between the gaseous phase and the oxygen content in molten iron can be calculated from equations (1) and (2) as the gaseous phase corresponds to Boudouard's equilibrium.

$$
\begin{aligned}
& \mathrm{O}+\mathrm{CO}=\mathrm{CO}_{2} \quad \text { (Carbon saturation). } \\
& \log K_{4}\left(=P_{\mathrm{CO}_{2}} / P_{\mathrm{co}} \times 0 \%\right)=9.018 / T-6.045
\end{aligned}
$$

The activity coefficient of oxygen can be calculated from equation (4) and Matoba and Banya's experimental equation (5) in the dilute solution:

$$
\begin{aligned}
& \mathrm{O}+\mathrm{CO}=\mathrm{CO}_{2} \quad \text { (Dilute solution). } \\
& \log K_{5}\left(=P_{\mathrm{Co}_{2}} / P_{\mathrm{Co}} \times a_{0}\right)=8,718 / T-4.762
\end{aligned}
$$

where $f_{0}=a_{0} / \underline{Q} \%$.

$$
\log f_{0}=\log K_{4}-\log K_{5}=300 / T-1.283
$$

The activity coefficient calculated from the above equation is shown in Table 7.

\section{(3) The equilibrium product [C \%] [O \%]}

The relation between carbon and oxygen in carbonsaturated molten iron is expressed as follows:

$$
\begin{aligned}
& \underline{\mathrm{C}}+\underline{\mathrm{Q}}=\mathrm{CO} \quad \text { (Carbon saturation) } \\
& \log K_{\mathbf{7}}=P_{\mathrm{co}} / \underline{\mathrm{C}} \% \times \underline{\mathrm{O}} \% .
\end{aligned}
$$

The values of $\log K_{7}$ obtained from the experiment are tabulated in Tables $3 \sim 6$. The relation between $\log K_{7}$ and $1 / T$ is graphically shown in Fig. 11, from which the following equation will be obtained as the value of equation (7):

$$
\log K_{\mathbf{7}}\left(=P_{\text {co }} / \underline{\mathrm{C}} \% \times \underline{\mathrm{Q}} \%\right)=1,239 / T+1.771 .
$$

As reported in many works, the equilibrium product [C \%] [O \%] is usually 0.00025 at $1600^{\circ} \mathrm{C}$ at lower

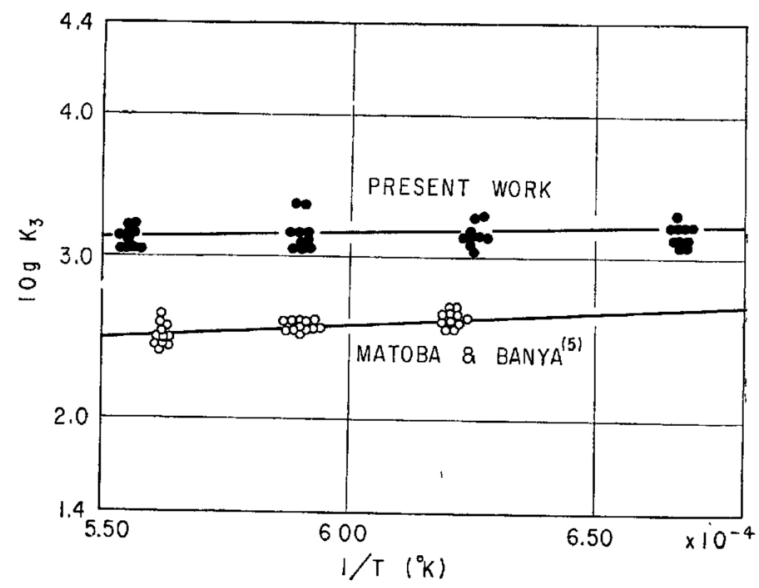

Fig. 10 Relation between $\log K_{3}$ and temperature. 


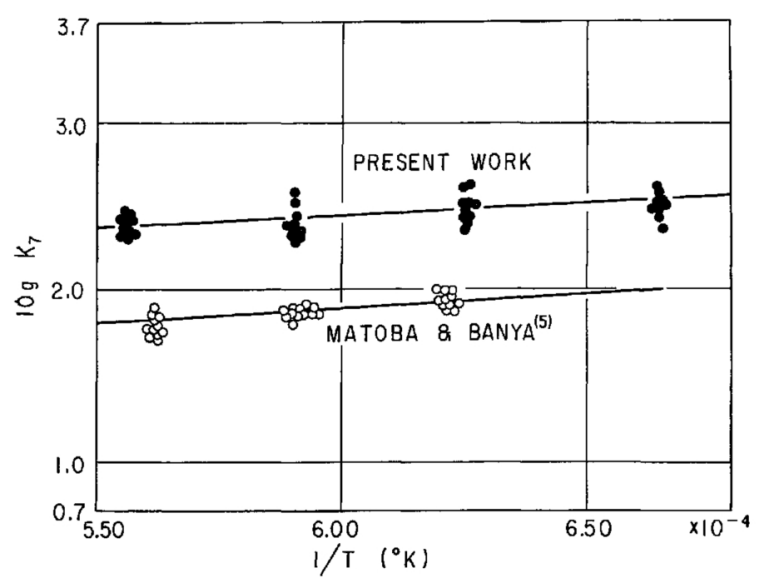

Fig. 11 Relation between $\log K_{7}$ and temperature.

carbon concentrations in the iron melt, but this experiment shows the value of 0.0043 by extrapolation. The activity coefficient of oxygen can be solved from Matoba and Banya's equation in the dilute solution.

$$
\begin{aligned}
& \underline{\mathrm{C}}+\underline{\mathrm{Q}}=\mathrm{CO} \text { (Dilute solution) } \\
& \begin{array}{r}
\log K_{8}\left(=P_{\mathrm{Co}} / f_{c} \times \underline{\mathrm{C}} \% \times f_{0} \times \underline{\mathrm{O}} \%\right) \\
=1.160 / T+2.003,
\end{array}
\end{aligned}
$$

where $K_{7} / K_{8}=f_{c} f_{0}$.

Accordingly,

$$
f_{0}=K_{7} / f_{c} \times K_{8}
$$

The values of $f_{0}$ calculated by substituting $f_{c}$ in Table 5 in the above equation are shown in Table 5 .

\section{Conclusion}

The relation between carbon and oxygen in carbonsaturated molten iron is measured in the temperature range of $1323 \sim 1520^{\circ} \mathrm{C}$. The results obtained are summarized as follows:
(1) The solubility of carbon is expressed as follows:

$$
\underline{\mathrm{C}} \%=1.33+2.59 \times 10^{-3} \times t^{\circ} \mathrm{C} .
$$

(2) The equilibrium relations between carbon and oxygen in carbon-saturated molten iron are expressed by the following equations;

$$
\begin{aligned}
& \mathrm{C}(\mathrm{g})+\underline{\mathrm{O}}=\mathrm{CO} . \\
& \log K_{3}\left(P_{\mathrm{CO}} / \underline{\mathrm{O}} \%\right)=613 / T+2.775 . \\
& \underline{\mathrm{O}}+\mathrm{CO}=\mathrm{CO}_{2} \quad(\text { Carbon saturation }) . \\
& \log K_{4}\left(=P_{\mathrm{CO}_{2}} / P_{\mathrm{co}} \times \underline{\mathrm{Q}} \%\right)=9,018 / T-6.045 . \\
& \underline{\mathrm{C}}+\underline{\mathrm{O}}=\mathrm{CO} \quad(\text { Carbon saturation }) . \\
& \log K_{7}\left(=P_{\mathrm{Co}} / \underline{\mathrm{C}} \% \times \underline{\mathrm{O}} \%\right)=1,239 / T+1.711 .
\end{aligned}
$$

(3) The equations for the activity coefficients of carbon and oxygen in carbon-saturated molten iron are defined as follows:

$$
\begin{aligned}
\log f_{c}= & -847 / T+2.055 \\
& -\log \left\{1.33+2.59 \times 10^{-3}(T-273)\right\} . \\
\log f_{0}= & 300 / T-1.283 .
\end{aligned}
$$

(4) The oxygen contents in carbon-saturated molten iron are considerably lower than those of previous works. Accordingly, the equilibrium nroduct $[\mathrm{C} \%] \times$ $[0 \%]$ is not very large and the activity coefficient is not very low.

(5) In regard to the sampling of carbon-saturated molten iron, it is necessary to further investigate the method to suppress the precipitation of graphite by solidifying as quickly as possible. As there is no reliable analytical method to determine such a low oxygen content as shown in this experiment, it is desired that an analytical procedure for determination of the oxygen content up to $0.0001 \%$ within the experimental error of $0.00005 \%$ be established. 